\title{
Is Osteosarcoma between the Two Peak Ages Different?
}

\author{
Taehun Kim¹, Hak Sun Chung1, Wan-Hyeong Cho², Dae-Geun Jeon², \\ So Hak Chung ${ }^{*}$ \\ ${ }^{1}$ Department of Orthopaedic Surgery, Kosin University Gospel Hospital, Busan, Republic of Korea \\ ${ }^{2}$ Department of Orthopaedic Surgery, Korea Cancer Center Hospital, Seoul, Republic of Korea \\ Email: *shchung@kosin.ac.kr
}

How to cite this paper: Kim, T., Chung, H.S., Cho, W.-H., Jeon, D.-G. and Chung, S.H. (2018) Is Osteosarcoma between the Two Peak Ages Different? Journal of Cancer Therapy, 9, 64-78.

https://doi.org/10.4236/jct.2018.91008

Received: October 16, 2017

Accepted: January 26, 2018

Published: January 29, 2018

Copyright $(9) 2018$ by authors and Scientific Research Publishing Inc. This work is licensed under the Creative Commons Attribution International License (CC BY 4.0).

http://creativecommons.org/licenses/by/4.0/

\begin{abstract}
Background: Unlike two known peak age groups (10 - 14 and older than 65 years of age), there was relatively scant attention in osteosarcoma patients between them, and previous reports had analyzed other than Asians. Therefore we conducted this study with Korean patients and focused on $20-40$ years of age, then investigated age-specific or race-specific meaningful outcomes. Materials and Methods: 379 patients who were newly diagnosed as osteosarcoma in two Korean major cancer hospitals from September 1986 to July 2015 with more than 2-year follow-up were retrospectively studied. There were 290 patients with 20 - 40 years of age, 60 patients aged 19 or younger, and 29 patients aged 41 or older. Age at diagnosis, gender, location of primary lesion, metastasis at diagnosis, histologic subtypes, histologic response were analyzed as prognostic factors by overall survival (OS) and event-free survival (EFS) rates. Results: Primary pelvic lesion and poor histologic response were significantly unfavorable prognostic factors, but not age-specific. However, proportion of metastasis at diagnosis was significantly highest in 20 - 40 years of age group. For the age at diagnosis, older patients presented poorer 5-year OS and EFS rates, but for 10-year, 20 - 40 years of age group showed unusually better prognosis than younger age's, with statistic significance in OS rates but not in EFS rates. Conclusion: Osteosarcoma patients with 20 - 40 years of age in Korea presented relatively better prognosis after longer-term 10-year despite their late diagnosis causing more metastasis at diagnosis, which emphasized expedite diagnosis and appropriate treatment to expect much better prognosis than peak age groups.
\end{abstract}

\section{Keywords}

Osteosarcoma, Age, Young Adult, Outcome, Prognosis 


\section{Introduction}

Osteosarcoma has a bimodal age distribution; the first peak is in the 10 - 14 years of age group which coincides with pubertal growth spurts, and the second peak is in adults older than 65 years of age who are more likely to represent a second malignancy, commonly related to Paget's disease [1]. Between these two peaks of age, 20 - 40 years of age group is generally considered as "young adults" [2]. Although cancer is the second most cause of death next to suicide in the young adult group, relatively less attention has caused its consequent relatively little improvement of survival rate in this group [3] [4]. Differences of pathogenesis and biology of cancers including osteosarcoma in this group, compared to younger and older peak groups, have emphasized importance of distinctly different approaches in early diagnosis, treatment and follow-up in these patients' group. Janeway et al. [5] have reported outcome of osteosarcoma in adolescent and young adult (AYA) patients, based on 1054 patients from Children's Oncology Group in North America. However, in this article, more than $90 \%$ of the patients were other than Asians (66\% of white, $14 \%$ of black, and $12 \%$ of Hispanic races). Therefore, we analyzed and reported the outcomes of osteosarcoma in 20 - 40 years of age group from the data in Kosin University Gospel Hospital and Korea Cancer Center Hospital. The most osteosarcoma patients of the two tertiary medical centers are enrolled in Korea, to compare the results with North America's and Europe's which would be helpful for awareness of their characteristics and decision of appropriate treatment modalities based on considerable risk factors in East Asians.

\section{Materials and Methods}

From September 1986 to July 2015, a total of 379 patients (220 males and 159 females) who were newly diagnosed as osteosarcoma in Kosin University Gospel Hospital and Korea Cancer Center Hospital, the two of the major Korean cancer hospitals with most osteosarcoma patients, were retrospectively enrolled in this study. All the patients had undergone an open biopsy, neoadjuvant chemotherapy, surgery, and adjuvant chemotherapy as a scheduled treatment protocols widely accepted based on the results of multi-institutional prospective trials [6] [7] [8], then were followed up for more than 2 years to be included in this study. Any patients with follow-up loss in less than 2 years or not completed the treatment protocols were excluded. Bone scan and chest CT were performed in every patient to check out distant metastasis, and positron emission tomography (PET) was also performed in recent cases.

The patients were divided into 3 groups according to their age at diagnosis. Group A included the patients aged 19 years or younger, and there were 60 patients ( 33 males and 27 females) in this group. Group B, mainly focused group in this study, included the patients aged 20 to 40 years, and there were 290 patients (174 males and 116 females) in this group. Group C included the patients aged 41 years or older, and there were 29 patients (13 males and 16 females) in this 
group. Mean age of group A, B, and C were 14.1, 27.7, and 49.0 years, respectively. Mean follow-up periods of group A, B, and C were 93.5, 118.3, and 90.7 months, respectively.

Oncologic results were analyzed by proportions of continuous disease free (CDF), no evidence of disease (NED), alive with disease (AWD), and dead of disease (DOD). Then, overall survival (OS) and event-free survival (EFS) rates of 5- and 10-year were estimated in each age group for comparison by Kaplan-Meier method [9]. OS rate was defined as the interval between diagnosis and death from any cause, and patients alive at date of last follow-up were censored at that time point. EFS rate was defined as the interval between diagnosis and disease progression or recurrence, and patients without disease recurrence at the date of last follow-up were censored at that date.

Potential prognostic factors were analyzed using cox regression. Clinical characteristics examined included age at diagnosis, gender, location of primary lesion (extremities, pelvis, and other parts), metastasis at diagnosis (with or without), histologic subtypes, histologic response (good if necrosis $\geq 90 \%$, poor if necrosis $<90 \%$ ) were also evaluated in a whole group and group B (20 to 40 years of age) to find out its characteristics. All analyses were performed using SPSS statistical analysis software (version 16.0, SPSS Inc, Chicago, IL).

\section{Results}

For the oncologic results, there were 52 (86.7\%), 4 (6.7\%), $0(0 \%)$, and $4(6.7 \%)$ cases of CDF, NED, AWD, and DOD in group A (aged 19 years or younger). In group B (aged 20 to 40 years), there were 179 (61.7\%), 37 (12.8\%), 2 (0.7\%), and $72(24.8 \%)$ cases of CDF, NED, AWD, and DOD, respectively. In group C (aged 41 years or older), there were 19 (65.5\%), 2 (6.9\%), 1 (3.4\%), and 7 (24.1\%) cases of CDF, NED, AWD, and DOD.

By Kaplan-Meier method, 5- and 10-year OS rates of the whole patients were 67.6\% (65.8\% - 69.4\%) and 39.3\% (37.1\% - 41.5\%), and 5- and 10-year EFS rates of them were $60.2 \%(58.2 \%-62.1 \%)$ and $36.4 \%(34.2 \%-38.6 \%)$, respectively. Same method was applied to each age group. In group A, 5- and 10-year OS rates were $71.7 \%(69.3 \%-74.1 \%)$ and $31.7 \%(28.1 \%-35.3 \%)$, and 5- and 10 -year EFS rates were $68.3 \%(65.8 \%-70.8 \%)$ and $30.0 \%(26.2 \%-33.8 \%)$. In group B, 5and 10 -year OS rates were $67.6 \%(65.5 \%-69.8 \%)$ and $42.1 \%(39.6 \%-44.6 \%)$, and 5- and 10-year EFS rates were 59.7\% (57.4\% - 62.1\%) and 39.0\% (36.5\%$41.5 \%)$. In group C, 5- and 10-year OS rates were 58.6\%(48.8\% - 68.4\%) and $27.6 \%(14.7 \%-40.5 \%)$, and 5- and 10-year EFS rates were 48.3\% (38.5\% - 58.1\%) and $24.1 \%(11.1 \%-37.1 \%)$. 5-year OS and EFS rates tended to be more deteriorated as the patients' age got older with statistical significance $(\mathrm{p}<0.001, \mathrm{p}<$ 0.001). However, for 10-year OS and EFS rates, group B (aged 20 - 40 years old) characteristically showed better results compared to other age groups, especially significant in 10 -year OS ( $\mathrm{p}=0.012$ ), but not statistically significant in 10-year EFS $(\mathrm{p}=0.081)($ Table 1 , Table 2$)$. 
Table 1. Characteristic of the study population and association of parameters age at diagnosis.

\begin{tabular}{|c|c|c|c|c|c|}
\hline \multirow[b]{2}{*}{ Characteristic } & \multirow{2}{*}{$\begin{array}{c}\text { All, } \mathrm{n}=379 \\
(\%)\end{array}$} & \multicolumn{3}{|c|}{ Age, No.(\%) } & \multirow[b]{2}{*}{$p^{a}$} \\
\hline & & $\begin{array}{l}<20 \text { years, } \\
\mathrm{n}=60(\%)\end{array}$ & $\begin{array}{c}20-40 \text { Years, } \\
\mathrm{n}=290(\%)\end{array}$ & $\begin{array}{l}\geq 40 \text { Years, } \\
n=29(\%)\end{array}$ & \\
\hline$<$ Sex $>$ & & & & & 0.251 \\
\hline Male & $220(58.0)$ & $33(55.0)$ & $174(60.0)$ & $13(44.8)$ & \\
\hline Female & $159(42.0)$ & $27(45.0)$ & $116(40.0)$ & $16(55.2)$ & \\
\hline$<$ Location $>$ & & & & & 0.014 \\
\hline Extremity & $343(90.5)$ & $59(98.3)$ & $259(89.3)$ & $25(86.2)$ & \\
\hline Pelvis & $24(6.3)$ & $1(1.7)$ & $21(7.2)$ & $2(6.9)$ & \\
\hline Etc. & $12(3.2)$ & $0(0.0)$ & $10(3.5)$ & $2(6.9)$ & \\
\hline$<$ Metastasis $>$ & & & & & 0.009 \\
\hline Localized $(\operatorname{meta}(-))$ & $272(71.8)$ & $52(86.7)$ & $197(67.9)$ & $23(79.3)$ & \\
\hline Metastasis(+) & $107(28.2)$ & $8(13.3)$ & $93(32.1)$ & $6(20.7)$ & \\
\hline$<$ Histologic Subtype $>$ & & & & & 0.003 \\
\hline $\mathrm{OB}^{*}$ & $248(65.4)$ & $41(68.3)$ & $197(67.9)$ & $10(34.5)$ & \\
\hline $\mathrm{FB}^{\dagger}$ & $54(14.2)$ & $7(11.7)$ & $39(13.4)$ & $8(27.6)$ & \\
\hline $\mathrm{CB}^{\ddagger}$ & $21(5.5)$ & $5(8.3)$ & $13(4.5)$ & $3(10.3)$ & \\
\hline Others & $35(9.2)$ & $1(1.7)$ & $30(10.3)$ & $4(13.8)$ & \\
\hline Unknown & $21(5.5)$ & $6(10.0)$ & $11(3.8)$ & $4(13.8)$ & \\
\hline$<$ Histologic Response $>$ & & & & & 0.843 \\
\hline $\begin{array}{l}\text { Good Response } \\
\text { (Necrosis } \geq 90 \%)\end{array}$ & $155(40.9)$ & $24(40.0)$ & $120(41.4)$ & $11(37.9)$ & \\
\hline $\begin{array}{c}\text { Poor Response } \\
(\text { Necrosis }<90 \%)\end{array}$ & $224(59.1)$ & $36(60.0)$ & $170(58.6)$ & $18(62.1)$ & \\
\hline
\end{tabular}

$\mathrm{OB}^{*}$ : osteoblastic, $\mathrm{FB}^{\dagger}$ : fibroblastic, $\mathrm{CB}^{\ddagger}$ : chondroblastic.

For gender, in the whole 220 males, 5- and 10-year OS rates were $65.5 \%$ and $36.4 \%$ and 5- and 10 -year EFS rates were $58.2 \%$ and $33.6 \%$. In the whole 159 females, 5- and 10-year OS rates were $67.3 \%$ and $43.4 \%$ and 5- and 10 -year EFS rates were $61.6 \%$ and $40.3 \%$. They did not show statistical significance in 5 - and 10 -year OS and EFS rates by gender $(\mathrm{p}=0.792, \mathrm{p}=0.236, \mathrm{p}=0.569, \mathrm{p}=0.225)$. In group B, 5- and 10-year OS rates were $66.7 \%$ and $40.8 \%$ and 5 - and 10 -year EFS rates were $58.6 \%$ and $37.9 \%$ in 174 males, and 5- and 10 -year OS rates were $64.7 \%$ and $44.0 \%$ and 5- and 10 -year EFS rates were $59.5 \%$ and $40.5 \%$ in 116 females. These also were not statistically significant by gender $(\mathrm{p}=0.823, \mathrm{p}=$ $0.680, \mathrm{p}=0.981, \mathrm{p}=0.749)$ (Table 1, Table 2).

For location of primary lesion, extremities counted for the most proportion in a whole group with 343 cases $(90.5 \%)$, following 24 cases $(6.33 \%)$ at pelvis, and 12 cases $(3.17 \%)$ at other parts such as rib, vertebra, or mandible, etc. 5- and 
Table 2. Parameters and their association with overall survival by univariate analysis.

\begin{tabular}{|c|c|c|c|c|c|c|c|c|c|}
\hline Characteristic & $\begin{array}{c}\text { Patients, } \\
\mathrm{n}=379(\%)\end{array}$ & $\begin{array}{c}\text { 5-Year OS* } \\
(\%)\end{array}$ & $p^{a}$ & $\begin{array}{c}10 \text {-Year OS* } \\
(\%)\end{array}$ & $p^{a}$ & 5-Year $\mathrm{EFS}^{\dagger}(\%)$ & $p^{a}$ & $\begin{array}{c}\text { 10-Year } \mathrm{EFS}^{\dagger} \\
(\%)\end{array}$ & $p^{a}$ \\
\hline$<$ Age $>$ & & & $<0.001$ & & 0.012 & & $<0.001$ & & 0.081 \\
\hline$<20$ years & $60(15.8)$ & $43(71.7)$ & & $19(31.7)$ & & $41(68.3)$ & & $18(30.0)$ & \\
\hline 20 - 40 Years & $290(76.5)$ & $196(67.6)$ & & $122(42.1)$ & & $173(59.7)$ & & $113(39.0)$ & \\
\hline$\geq 40$ Years & $29(7.7)$ & $17(58.6)$ & & $8(27.6)$ & & $14(48.2)$ & & $7(24.1)$ & \\
\hline$<$ Sex $>$ & & & 0.792 & & 0.236 & & 0.569 & & 0.225 \\
\hline Male & $220(58.0)$ & $144(65.5)$ & & $80(36.4)$ & & $128(58.2)$ & & $74(33.6)$ & \\
\hline Female & $159(42.0)$ & $107(67.3)$ & & $69(43.4)$ & & $98(61.6)$ & & $74(40.3)$ & \\
\hline$<$ Location $>$ & & & 0.003 & & 0.542 & & 0.003 & & 0.240 \\
\hline Extremity & $343(90.5)$ & $237(69.1)$ & & $139(40.4)$ & & $214(62.5)$ & & $129(37.5)$ & \\
\hline Pelvis & $24(6.3)$ & $9(37.5)$ & & $7(29.2)$ & & $7(29.2)$ & & $5(20.8)$ & \\
\hline Etc & $12(3.2)$ & $6(50.0)$ & & $5(41.7)$ & & $5(41.7)$ & & $5(41.7)$ & \\
\hline$<$ Metastasis $>$ & & & $<0.001$ & & $<0.001$ & & $<0.001$ & & $<0.001$ \\
\hline Localized (meta $(-))$ & $272(71.8)$ & $209(76.8)$ & & $129(47.4)$ & & $209(76.8)$ & & $129(47.4)$ & \\
\hline Metastasis (+) & $107(28.2)$ & $19(17.8)$ & & $16(15.1)$ & & $15(14.9)$ & & $8(7.5)$ & \\
\hline$<$ Histologic Subtype $>$ & & & 0.577 & & $<0.001$ & & 0.498 & & 0.024 \\
\hline $\mathrm{OB}^{\ddagger}$ & $243(65.4)$ & $167(68.5)$ & & $102(41.9)$ & & $152(62.5)$ & & 97 (39.9) & \\
\hline $\mathrm{FB}^{\S}$ & $54(14.2)$ & $32(59.3)$ & & $10(18.5)$ & & $29(53.7)$ & & $9(16.7)$ & \\
\hline $\mathrm{CB}^{\prime \prime}$ & $21(5.5)$ & $15(71.4)$ & & $14(61.9)$ & & $10(47.6)$ & & $9(42.9)$ & \\
\hline Others & $35(9.2)$ & $21(60.0)$ & & $13(37.1)$ & & $19(54.3)$ & & $12(34.3)$ & \\
\hline Unknown & $21(5.5)$ & $13(61.9)$ & & $9(42.9)$ & & $13(61.9)$ & & $9(42.9)$ & \\
\hline$<$ Histologic Response $>$ & & & $<0.001$ & & $<0.001$ & & 0.007 & & $<0.001$ \\
\hline $\begin{array}{l}\text { Good Response } \\
\text { (Necrosis } \geq 90 \%)\end{array}$ & $144(40.9)$ & $119(82.6)$ & & $95(65.8)$ & & $118(81.9)$ & & $94(65.2)$ & \\
\hline $\begin{array}{l}\text { Poor Response } \\
(\text { Necrosis }<90 \%)\end{array}$ & $224(59.1)$ & $128(57.1)$ & & $47(21.0)$ & & $101(45.1)$ & & $37(16.5)$ & \\
\hline
\end{tabular}

$\mathrm{OS}^{*}$ : overall survival, $\mathrm{EFS}^{\dagger}$ : event-free survival, $\mathrm{OB}^{\ddagger}$ : osteoblastic, $\mathrm{FB}^{\S}$ : fibroblastic, $\mathrm{CB}^{\prime \prime}$ : chondroblastic.

10-year OS rates and 5- and 10-year EFS rates of the whole groups were $69.1 \%$, $40.4 \%, 62.5 \%$, and $37.5 \%$ at extremities, $37.5 \%, 29.2 \%, 29.2 \%$, and $20.8 \%$ at pelvis, and $50.0 \%, 41.7 \%, 41.7 \%$, and $41.7 \%$ at other parts. Patients with primary lesions at pelvis presented worst outcome, and this was statistically significant in 5 -year OS and EFS rates by the location $(\mathrm{p}=0.003, \mathrm{p}=0.003)$. In group $\mathrm{B}$, there were 259 cases $(89.3 \%)$ at extremities, $21(7.2 \%)$ at pelvis, and $10(3.5 \%)$ at other parts. 5- and 10-year OS rates and 5- and 10-year EFS rates of group B were $69.1 \%, 43.0 \%, 61.9 \%$, and $40.0 \%$ at extremities, $38.1 \%, 33.3 \%, 28.6 \%$, and $23.8 \%$ at pelvis, and $50.0 \%, 50.0 \%, 50.0 \%$, and $50.0 \%$ at other parts. This group also showed most unfavorable outcome at pelvic osteosarcoma patients, and this was statistically significant in 5-year OS and EFS rates by the location $(\mathrm{p}<0.001, \mathrm{p}<$ 0.001) (Tables 1-3). 
Table 3. Location of primary lesions by age group.

\begin{tabular}{|c|c|c|c|c|c|c|c|c|c|}
\hline \multicolumn{10}{|c|}{$<20$ years } \\
\hline & $\mathrm{n}=60(\%)$ & 5 -Year OS* $(\%)$ & $p^{a}$ & $10-$ Year OS* $(\%)$ & $p^{a}$ & 5-Year EFS ${ }^{\dagger}(\%)$ & $p^{a}$ & $10-$ Year EFS ${ }^{\dagger}(\%)$ & $p^{a}$ \\
\hline Location & & & 0.367 & & 0.875 & & 0.691 & & 0.973 \\
\hline Extremity & $59(98.3)$ & $50(72.9)$ & & $19(32.2)$ & & $41(69.5)$ & & $18(30.5)$ & \\
\hline Pelvis & $1(1.7)$ & $0(0.0)$ & & $0(0.0)$ & & $0(0.0)$ & & $0(0.0)$ & \\
\hline Etc & $0(0.0)$ & - & & - & & - & & - & \\
\hline \multicolumn{10}{|c|}{ 20-40 Years } \\
\hline & $\mathrm{n}=290(\%)$ & 5 -Year OS* (\%) & $p^{a}$ & 10 -Year OS* (\%) & $p^{a}$ & 5-Year $\mathrm{EFS}^{\dagger}(\%)$ & $p^{a}$ & 10 -Year EFS ${ }^{\dagger}(\%)$ & $p^{a}$ \\
\hline Location & & & $<0.001$ & & $<0.001$ & & $<0.001$ & & $<0.001$ \\
\hline Extremity & $259(89.3)$ & $179(69.1)$ & & $111(43.0)$ & & $160(61.9)$ & & $104(40.0)$ & \\
\hline Pelvis & $21(7.2)$ & $8(38.1)$ & & $7(33.3)$ & & $6(28.6)$ & & $5(23.8)$ & \\
\hline Etc & $10(3.5)$ & $5(50.0)$ & & $5(50.0)$ & & $5(50.0)$ & & $5(50.0)$ & \\
\hline \multicolumn{10}{|c|}{$\geq 40$ Years } \\
\hline & $\mathrm{n}=29(\%)$ & 5-Year OS* (\%) & $p^{a}$ & $10-$ Year OS* $(\%)$ & $p^{a}$ & 5-Year $\mathrm{EFS}^{\dagger}(\%)$ & $p^{a}$ & 10 -Year EFS ${ }^{\dagger}(\%)$ & $p^{a}$ \\
\hline Location & & & 0.157 & & 0.004 & & 0.003 & & 0.004 \\
\hline Extremity & $25(86.2)$ & $15(60.0)$ & & $8(32.0)$ & & $13(52.0)$ & & $7(28.0)$ & \\
\hline Pelvis & $2(6.9)$ & $1(50.0)$ & & $0(0.0)$ & & $1(50.0)$ & & $0(0.0)$ & \\
\hline Etc & $2(6.9)$ & $1(50.0)$ & & $0(0.0)$ & & $0(0.0)$ & & $0(0.0)$ & \\
\hline
\end{tabular}

$\mathrm{OS}^{*}$ : overall survival, $\mathrm{EFS}^{\dagger}$ : event-free survival.

For metastasis at diagnosis, 107 patients (28.2\%) in a whole group and 93 patients $(32.1 \%)$ in group B were found metastasis when osteosarcoma was diagnosed. In group A and C, there were 8 (13.3\%) and 6 (20.7\%) metastatic patients. There were statistically significantly more proportion of metastasis at diagnosis in group B compared to the other age groups $(p=0.009)$. For location of metastatic lesions, lung was the most commonly involved; $84.1 \%$ in a whole group and $84.9 \%$ in group B. In a whole group, 5- and 10-year OS rates and 5- and 10 -year EFSs rate in the patients with metastasis presented $17.8 \%, 15.1 \%, 14.9 \%$, and $7.5 \%$ and those in patients without metastasis showed $76.8 \%, 47.4 \%, 76.8 \%$, and $47.4 \%$. In group A, 5- and 10-year OS rates and 5- and 10-year EFS rates in the patients with metastasis presented $37.5 \%, 12.5 \%, 12.5 \%$, and $0.0 \%$ and those in patients without metastasis showed $79.9 \%, 34.6 \%, 76.9 \%$, and $34.6 \%$. In group $\mathrm{B}, 5$ - and 10-year OS rates and 5- and 10-year EFS rates in the patients with metastasis presented $37.6 \%, 18.3 \%, 16.1 \%$, and $8.6 \%$ and those in patients without metastasis showed $76.7 \%, 52.8 \%, 76.7 \%$, and $52.8 \%$. In group C, 5- and 10-year OS rates and 5- and 10-year EFS rates in the patients with metastasis presented $37.5 \%, 12.5 \%, 0.0 \%$, and $0.0 \%$ and those in patients without metastasis showed $60.9 \%, 30.4 \%, 60.9 \%$, and $30.4 \%$. The survival rates in metastatic patients was significantly poorer than those of non-metastatic patients in group $B(p<0.001)$, however, this tendency was also found in the other age groups (Table 1, Table 2, Table 4). 
Table 4. Metastasis at diagnosis by age group.

\begin{tabular}{|c|c|c|c|c|c|c|c|c|c|}
\hline \multicolumn{10}{|c|}{$<20$ years } \\
\hline & $\mathrm{n}=60(\%)$ & 5 -Year OS* $(\%)$ & $p^{a}$ & $10-$ Year OS* $(\%)$ & $p^{a}$ & 5-Year $\mathrm{EFS}^{\dagger}(\%)$ & $p^{a}$ & $10-Y e a r \mathrm{EFS}^{\dagger}(\%)$ & $p^{a}$ \\
\hline Metastasis & & & 0.028 & & 0.399 & & 0.001 & & 0.115 \\
\hline Localized & $52(86.7)$ & $42(79.9)$ & & $18(34.6)$ & & $40(76.9)$ & & $18(34.6)$ & \\
\hline Metastasis(+) & $8(13.3)$ & $3(37.5)$ & & $1(12.5)$ & & $1(12.5)$ & & $0(0.0)$ & \\
\hline \multicolumn{10}{|c|}{$20-40$ Years } \\
\hline & $\mathrm{n}=290(\%)$ & 5 -Year OS* $(\%)$ & $p^{a}$ & $10-$ Year OS* $(\%)$ & $p^{a}$ & 5-Year EFS $\dagger(\%)$ & $p^{a}$ & $10-$ Year EFS $\dagger(\%)$ & $p^{a}$ \\
\hline Metastasis & & & 0.002 & & $<0.001$ & & $<0.001$ & & $<0.001$ \\
\hline Localized & $197(67.9)$ & $151(76.7)$ & & $104(52.8)$ & & $155(78.7)$ & & $104(52.8)$ & \\
\hline Metastasis $(+)$ & $93(32.1)$ & $35(37.6)$ & & $17(18.3)$ & & $15(16.1)$ & & $8(8.6)$ & \\
\hline \multicolumn{10}{|c|}{$\geq 40$ Years } \\
\hline & $\mathrm{n}=29(\%)$ & 5 -Year OS* (\%) & $p^{a}$ & $10-$ Year OS* $(\%)$ & $p^{a}$ & 5-Year EFS $\dagger(\%)$ & $p^{a}$ & $10-Y e a r \mathrm{EFS}^{\dagger}(\%)$ & $p^{a}$ \\
\hline Metastasis & & & 0.455 & & 0.874 & & 0.028 & & 0.310 \\
\hline Localized & $23(79.3)$ & $14(60.9)$ & & $7(30.4)$ & & $14(60.9)$ & & $7(30.4)$ & \\
\hline Metastasis(+) & $6(20.7)$ & $2(33.3)$ & & $1(16.7)$ & & $0(0.0)$ & & $0(0.0)$ & \\
\hline
\end{tabular}

$\mathrm{OS}^{*}$ : overall survival, $\mathrm{EFS}^{\dagger}$ : event-free survival.

For histologic subtypes, there were 248 (65.4\%) osteoblastic (OB) subtype, 54 (14.2\%) fibroblastic (FB) subtype, 21 (5.6\%) chondroblastic (CB) subtype, 35 (9.2\%) other subtypes (mixed, telangiectatic, malignant-fibrous histiocytoma-like, small cell, etc.), and 21 (5.6\%) unknown subtypes in a whole patients. In group $\mathrm{A}$, there were $41(68.3 \%)$ of OB, 7 (11.7\%) of FB, 5 (8.3\%) of CB, 1 (1.7\%) of others, and $6(10.0 \%)$ of unknowns. In group $B$, there were $197(67.9 \%)$ of OB, $39(13.4 \%)$ of $\mathrm{FB}, 13(4.5 \%)$ of $\mathrm{CB}, 30(10.3 \%)$ of others, and $11(3.9 \%)$ of unknowns. In group $\mathrm{C}$, there were 10 (34.5\%) of OB, 8 (27.6\%) of $\mathrm{FB}, 3(10.3 \%)$ of $\mathrm{CB}, 4(13.8 \%)$ of others, and 4 (13.8\%) of unknowns. OB counted for the highest proportion in group B, but that value was similar to group A's. For survival rates according to major histologic subtypes in a whole group, 5- and 10-year OS rates and 5- and 10-year EFS rates were $68.5 \%, 41.9 \%, 62.5 \%$, and $39.9 \%$ at OB subtype, $59.3 \%, 18.5 \%, 53.7 \%$, and $16.7 \%$ at $\mathrm{FB}, 71.4 \%, 61.9 \%, 47.6 \%$, and $42.9 \%$ at $\mathrm{CB}, 60.0 \%, 37.1 \%, 54.3 \%$, and $34.3 \%$ at others, and $61.9 \%, 42.9 \%, 61.9 \%$, and $42.9 \%$ at unknown subtype. In group B, 5- and 10-year OS rates and 5- and 10 -year EFS rates were $68.5 \%, 45.2 \%, 62.4 \%$, and $43.1 \%$ at OB, $53.8 \%, 20.5 \%$, $48.7 \%$, and $17.9 \%$ at $\mathrm{FB}, 76.9 \%, 69.2 \%, 46.2 \%$, and $46.2 \%$ at $\mathrm{CB}, 60.0 \%, 33.3 \%$, $53.3 \%$, and $30.0 \%$ at others, and $63.6 \%, 54.5 \%, 63.6 \%$, and $54.5 \%$ at unknown subtypes. In group A, 5- and 10-year OS rates and 5- and 10-year EFS rates were $73.2 \%, 31.7 \%, 68.3 \%$, and $29.3 \%$ at $\mathrm{OB}, 71.4 \%, 14.3 \%, 71.4 \%$, and $14.3 \%$ at $\mathrm{FB}$, $40.0 \%, 20.0 \%, 40.0 \%$, and $20.0 \%$ at CB, $100.0 \%, 100.0 \%, 100.0 \%$, and $100.0 \%$ at others, and $83.3 \%, 50.0 \%, 83.3 \%$, and $50.0 \%$ at unknown. In group C, $5-$ and 10-year OS rates and 5- and 10-year EFS rates were 50.0\%, 20.0\%, 40.0\%, and 
$20.0 \%$ at $\mathrm{OB}, 75.0 \%, 12.5 \%, 62.5 \%$, and $12.5 \%$ at $\mathrm{FB}, 100.0 \%, 100.0 \%, 66.7 \%$, and $66.7 \%$ at $\mathrm{CB}, 50.0 \%, 50.0 \%, 50.0 \%$, and $50.0 \%$ at others, and $25.0 \%, 0.0 \%, 25.0 \%$, and $0.0 \%$ at unknown. With comparing survival rates among the subtypes in group B, patients with chondroblastic (CB) subtype presented better outcomes than the other subtypes, and this was statistically significant $(\mathrm{p}<0.001)$ (Table 1, Table 2, Table 5).

For histologic response with a cutoff value of $90 \%$ necrosis, patients with good response (necrosis $\geq 90 \%$ ) and poor response (necrosis $<90 \%$ ) were $155(40.9 \%$ ) and $224(59.1 \%)$ in a whole group, $24(40.0 \%)$ and $36(60.0 \%)$ in group A, 120 (41.4\%) and $170(58.6 \%)$ in group B, and 11 (37.9\%) and 18 (62.1\%) in group C. There was no significant difference in proportion of good and poor histologic response among the three age groups $(p=0.843)$. However, survival rates were more unfavorable in poorly responded patients in every group with statistical

Table 5. Histologic subtype by age group.

\begin{tabular}{|c|c|c|c|c|c|c|c|c|c|}
\hline \multicolumn{10}{|c|}{$<20$ Years } \\
\hline & $\mathrm{n}=60(\%)$ & 5 -Year OS* $(\%)$ & $p^{a}$ & $10-$ Year OS* $(\%)$ & $p^{a}$ & 5-Year $\mathrm{EFS}^{\dagger}(\%)$ & $p^{a}$ & $10-$ Year EFS ${ }^{\dagger}(\%)$ & $p^{a}$ \\
\hline Subtype & & & 0.005 & & 0.005 & & 0.005 & & 0.004 \\
\hline OB $\ddagger$ & $41(68.3)$ & $30(73.2)$ & & $13(31.7)$ & & $28(68.3)$ & & $12(29.3)$ & \\
\hline FBS & $7(11.7)$ & $5(71.4)$ & & $1(14.3)$ & & $5(71.4)$ & & $1(14.3)$ & \\
\hline $\mathrm{CB} / /$ & $5(8.3)$ & $2(40.0)$ & & $1(20.0)$ & & $2(40.0)$ & & $1(20.0)$ & \\
\hline Others & $1(1.7)$ & $1(100.0)$ & & $1(100.0)$ & & $1(100.0)$ & & $1(100.0)$ & \\
\hline Unknown & $6(10.0)$ & $4(83.3)$ & & $3(50.0)$ & & $4(83.3)$ & & $3(50.0)$ & \\
\hline \multicolumn{10}{|c|}{20 - 40 Years } \\
\hline & $\mathrm{n}=290(\%)$ & 5 -Year OS* $(\%)$ & $p^{a}$ & $10-$ Year OS* $(\%)$ & $p^{a}$ & 5-Year $\mathrm{EFS}^{\dagger}(\%)$ & $p^{a}$ & $10-Y e a r \mathrm{EFS}^{\dagger}(\%)$ & $p^{a}$ \\
\hline Subtype & & & $<0.001$ & & $<0.001$ & & $<0.001$ & & $<0.001$ \\
\hline $\mathrm{OB}^{\ddagger}$ & $197(67.9)$ & $135(68.5)$ & & $89(45.2)$ & & $123(62.4)$ & & $85(43.1)$ & \\
\hline $\mathrm{FB}^{\S}$ & $39(13.4)$ & $21(53.8)$ & & $8(20.5)$ & & $19(48.7)$ & & $7(17.9)$ & \\
\hline $\mathrm{CB}^{\prime \prime}$ & $13(4.5)$ & $10(76.9)$ & & $9(69.2)$ & & $6(46.2)$ & & $6(46.2)$ & \\
\hline Others & $30(10.3)$ & $18(60.0)$ & & $10(33.3)$ & & $16(53.3)$ & & $9(30.0)$ & \\
\hline Unknown & $11(13.8)$ & $7(63.6)$ & & $6(54.5)$ & & $7(63.6)$ & & $6(54.5)$ & \\
\hline \multicolumn{10}{|c|}{$\geq 40$ Years } \\
\hline & $\mathrm{n}=29(\%)$ & 5 -Year $\mathrm{OS}^{\star}(\%)$ & $p^{a}$ & $10-$ Year OS* $(\%)$ & $p^{a}$ & 5-Year $\mathrm{EFS}^{\dagger}(\%)$ & $p^{a}$ & $10-$ Year $\mathrm{EFS}^{\dagger}(\%)$ & $p^{a}$ \\
\hline Subtype & & & 0.894 & & 0.060 & & 0.253 & & 0.060 \\
\hline $\mathrm{OB}^{\ddagger}$ & $10(34.5)$ & $5(50.0)$ & & $2(20.0)$ & & $4(40.0)$ & & $2(20.0)$ & \\
\hline $\mathrm{FB}^{\S}$ & $8(27.6)$ & $6(75.0)$ & & $1(12.5)$ & & $5(62.5)$ & & $1(12.5)$ & \\
\hline $\mathrm{CB}^{\prime \prime}$ & $3(10.3)$ & $3(100.0)$ & & $3(100.0)$ & & $2(66.7)$ & & $2(66.7)$ & \\
\hline Others & $4(13.8)$ & $2(50.0)$ & & $2(50.0)$ & & $2(50.0)$ & & $2(50.0)$ & \\
\hline Unknown & $4(5.5)$ & $1(25.0)$ & & $0(0.0)$ & & $1(25.0)$ & & $0(0.0)$. & \\
\hline
\end{tabular}

$\mathrm{OS}^{\star}$ : overall survival, $\mathrm{EFS}^{\dagger}$ : event-free survival, $\mathrm{OB}^{\ddagger}$ : osteoblastic, $\mathrm{FB}^{\S}$ : fibroblastic, $\mathrm{CB}^{\prime \prime}$ : chondroblastic. 
significance, except for 5-year OS and EFS rates of group C. In the whole groups, 5- and 10-year OS rates and 5- and 10-year EFS rates were 82.6\%, 65.8\%, 81.9\%, and $65.2 \%$ at good response but $57.1 \%, 21.0 \%, 45.1 \%$, and $16.5 \%$ at poor response. In group A, these rates were $87.5 \%, 54.2 \%, 87.5 \%$, and $54.2 \%$ at good response but $61.1 \%, 16.7 \%, 55.6 \%$, and $13.9 \%$ at poor response. In group $\mathrm{B}$, the rates were $82.5 \%, 69.2 \%, 81.7 \%$, and $68.3 \%$ at good response but $57.1 \%, 22.9 \%$, $44.1 \%$, and $18.2 \%$ at poor response, respectively. And they were $72.7 \%, 54.6 \%$, $72.7 \%$, and $54.6 \%$ at good response but $50.0 \%, 11.1 \%, 33.3 \%$, and $5.6 \%$ at poor response in group $\mathrm{C}$ (Table 1 , Table 2, Table 6).

\section{Discussion}

Osteosarcoma is the most common childhood malignancy of the bone [10], and occurs eighth in general incidence among all childhood cancers, accounts for $2.4 \%$, and death rates for osteosarcoma have been decreasing by approximately $1.3 \%$ per year. The 5 -year survival rate using a multidisciplinary approach varies from $60 \%$ to $70 \%$ [7] [11].

For the outcomes of osteosarcoma, many published articles mainly focused on two peak age groups, 10 - 14 years of age (early adolescence) and older than 65 years of age (elderly populations). However, there had not been many reports about outcomes of the age group between the two peak age groups, except for the massive study by Janeway et al. [5] about outcomes of osteosarcoma in the patients aged 18 to 30 years in North America. Between the age of 15 and 65, we authors focused on the patients aged 20 to 40 years on Korean social background.

Table 6. Histologic response by age group.

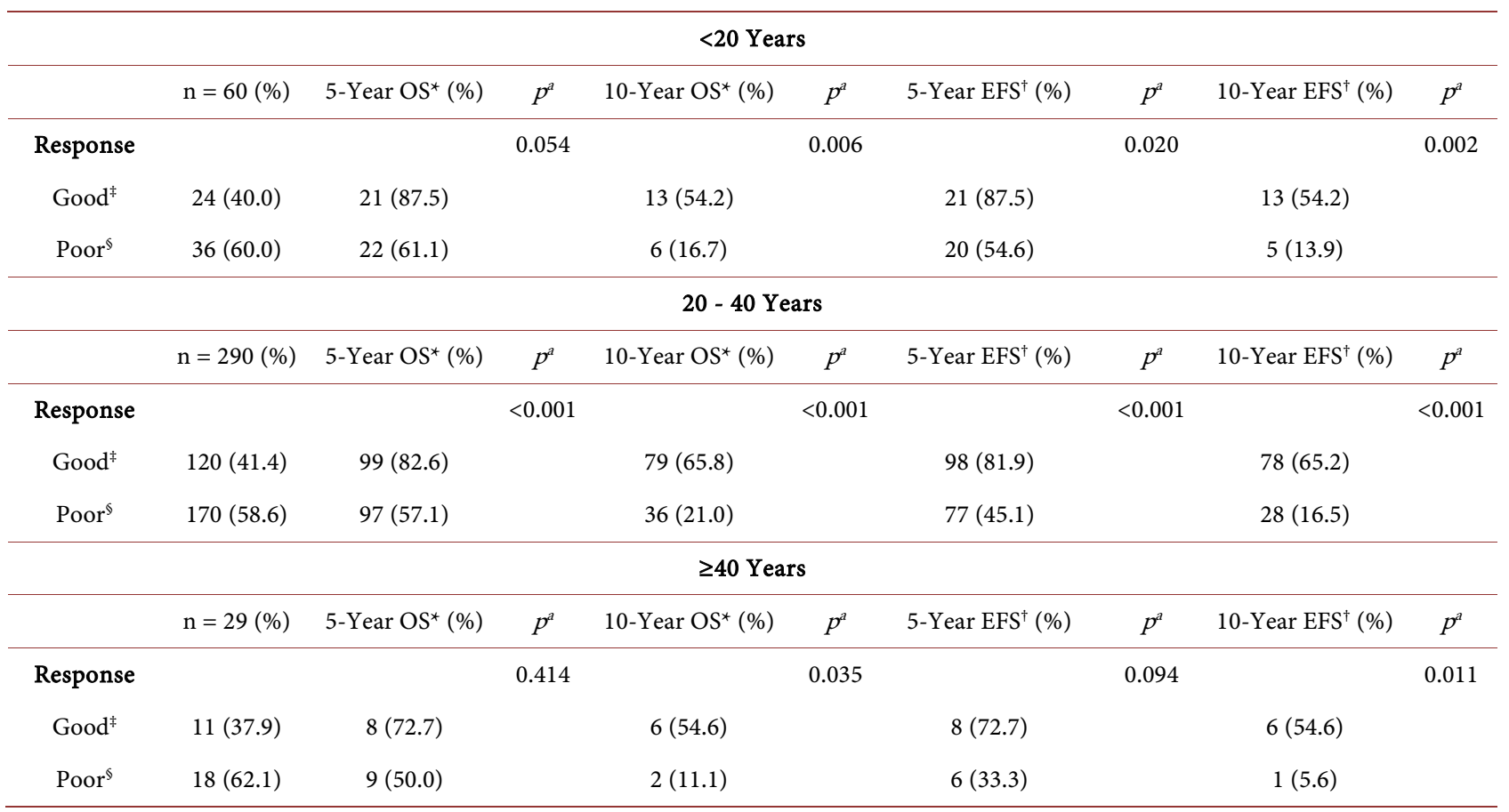

OS$^{\star}$ : overall survival, EFS ${ }^{\dagger}$ e event-free survival, Good ${ }^{\ddagger}$ : Necrosis $\geq 90 \%$, Poor ${ }^{\S}$ : Necrosi $<90 \%$. 
Because in Korea (or other East Asian countries), this age group population have just graduated high school and start to be independent from their parents financially and get married to have their own family and have jobs recently, which make them difficult to visit hospital quickly when they suffer pain or other symptoms. Scant social attention and relatively low incidence of osteosarcoma paradoxically have emphasized more concern about these 20 - 40 years of age group in Korea, therefore an analysis of this young adult patients with osteosarcoma is noteworthy.

It is well known that older patients with osteosarcoma have more unfavorable prognosis [12] [13]. Our study also confirmed that 5-year OS and EFS rates were decreased as the patients' age were older $(71.7 \%$ and $68.3 \%$ in $\leq 19$ years old, $67.6 \%$ and $59.7 \%$ in 20 - 40 years old, and $58.6 \%$ and $48.3 \%$ in $\geq 41$ years old, respectively). However, for 10 -year OS and EFS rates, it is interesting that these longer-term prognosis of 20 - 40 years of age group changed to be better ( $42.1 \%$ and $39.0 \%$ ) than younger or older age groups ( $31.7 \%$ and $30.0 \%$ in $\leq 19$ years old, $27.6 \%$ and $24.1 \%$ in $\geq 41$ years old respectively), especially for 10 -year OS being significant $(p=0.012)$. In spite that statistical significance was not found at 10 -year EFS ( $p=0.081$ ), we think that this outcome can be meaningful. Because even the proportion of metastasis at diagnosis was highest in this 20 - 40 years of aged group, their prognosis was more favorable than the other age groups. We assume that this phenomenon might be explained by the young adult patients' relatively better general health status. Similar report by Hagleitner et al. [13] in Netherland also concluded that younger patients had significantly better outcome than older patients, but their statement was depend on OS and EFS rates of 5-year, which means that longer-term follow-up such as our 10-year OS and EFS rates might have produced different outcomes. In a study by Hartling et al. [14] at M.D. Anderson Cancer Center, patient group of aged 21 - 40 years presented relatively better OS rate and less RR (risk ratio) than the other age groups, although these were not statistically significant values and they concluded that age at diagnosis did not seem to be a significant prognostic factor. When considering mono-ethnicity in Korea or other East Asian countries in comparison with other studies investigated through more studies.

For the location of primary lesions, it is well known that most of the osteosarcoma occurs at the extremities. Picci [15] reported that about $85 \%$ of the osteosarcoma patients had tumors located in the extremities, and so was our result ( $90.5 \%$ in a whole group and $89.3 \%$ in a group with 20 - 40 years of age). However, we think the locational focus should be set on the pelvis, which shows the worst prognosis. Osteosarcoma at pelvis accounts for $4 \%$ to $10 \%$ of all osteosarcomas [16]. In our study, the proportions of primary lesion at the pelvis presented similar to other reports; $6.3 \%$ ( 24 of 343 patients) in a whole group and $7.2 \%$ (21 of 259 patients) in group with 20 - 40 years of age. For the outcome, there is a perception that pelvic osteosarcomas have more dismal prognosis than the other sites [17]. Among the studies with relatively more cases, Ozaki et al. 
[18] reported that 5-year OS and progression-free survival rates were $27 \%$ and 19\% based on 76 patients with high-grade pelvic osteosarcoma registered in the Cooperative Osteosarcoma Study Group (COSS). Parry et al. [19] also analyzed 121 pelvic osteosarcoma patients (mean age of 29.3 (9 to 76) years) and stated that disease-specific survival rate of 5 -year was $27.2 \%$. In our study, the survival rates in a whole group and in group with 20 - 40 years of age were not significantly different from those studies; 5- and 10-year OS rates were $37.5 \%$ and $29.2 \%$ in a whole group and $38.1 \%$ and $33.3 \%$ in group B, 5- and 10 -year EFS rates were $29.2 \%$ and $20.8 \%$ in a whole group and $28.6 \%$ and $23.8 \%$ in group B. However, compared to cases with lesions at the extremities, the survival rates of the pelvic osteosarcoma were much more unfavorable with statistical significance $(\mathrm{p}<0.001)$.

About $15 \%-20 \%$ of patients are metastatic at diagnosis [15]. In contrast to approximately $75 \%$ and $65 \%$ of 5 -year OS and EFS rates for patients with non-metastatic disease by several studies [20] [21], Mialou et al. [22] reported that 5-year OS and EFS rates of 78 patients with metastatic osteosarcoma aged < 20 years were $19 \%$ and $14 \%$. Our study showed proportion of metastasis at diagnosis was $13.3 \%$ (8 of 60) in group A and 20.7\% (6 of 29) in group C, but increased to $32.1 \%$ (93 of 290 ) in group B of $20-40$ years of age with statistical significance $(\mathrm{p}=0.009)$. We think that this result may be due to late detection of osteosarcoma in young adult patients, probably because of relatively late visit to the hospital when pain or other suspicious symptoms presented. Regardless of the age, every age group presented significantly more unfavorable prognosis when metastasis was found at diagnosis $(\mathrm{p}<0.001)$. This outcome means that metastasis at diagnosis is a significant unfavorable prognostic factor not only in the young adult but also for the whole osteosarcoma patients.

For the proportion of histologic subtypes, Hauben et al. [23] analyzed 568 patients for whom subtype was available then reported 404 (71\%) were of the conventional subtype, $54(10 \%)$ were chondroblastic, 53 (9\%) had fibroblastic tumors and the remainder consisted of rare subtypes. Our data also presented similar proportion, not only in the whole group but also in the group B. For the relationship of histologic subtypes and their prognosis, there seem to be controversial in the opinions among the previous studies. Parry et al. [19] reported that best 5-year disease-specific survival rate was among osteoblastic subtypes at $35.2 \%$, followed by chondroblastic of $24.3 \%$, and non-defined at $23.6 \%$. Hauben et al. [23] reported that there were a higher proportion of good responders in the fibroblastic group and a lower proportion of good responders in the chondroblastic group in comparison with the conventional subtype, and concluded that chondroblastic subtype experienced better survival. In contrast, Bacci et al. [24] reported that 5-year OS rate was significantly higher in fibroblastic (83\%) tumors than in osteoblastic $(62 \%)$ and chondroblastic $(60 \%)$ tumors, and 5-year OS rate was significantly higher in good responders than in poor responders in all subtypes except the chondroblastic subtype. In our study, slightly different patterns of prognosis were found among the subtypes accord- 
ing to OS and EFS rates. Chondroblastic subtype showed relatively better prognosis with 10 -year OS and EFS rates of $61.9 \%$ and $42.9 \%$, and fibroblastic subtype showed relatively poorer prognosis with 10-year OS and EFS rates of 18.5\% and $16.7 \%$. However, these were not statistically significant $(\mathrm{p}<0.001, \mathrm{p}=$ 0.024). Therefore we think that more studies should be performed to establish the exact relationship between the histologic subtypes and their prognosis.

In determination of histologic response to chemotherapy, evaluation was performed by comparing necrosis of resected tumor with the biopsy specimen. For cutoff point in assessment of chemotherapeutic effect, many studies use $90 \%$ necrosis as standard [25] [26] [27], therefore we authors also used this point as a cutoff value determination whether histological responses were good or poor. Although there was one recent article stating that histological necrosis after chemotherapy did not significantly influence survival [28], histological response seems to be one of the generally-accepted significant prognostic factors in osteosarcoma [29] [30]. In our study, the patients with poor histologic response presented much more unfavorable survival rates than those with good histologic response, regardless of the age, and these results were statistically significant ( $\mathrm{p}=$ 0.018). This tendency means that histologic response is also a significant unfavorable prognostic factor not only in the young adult but also for the whole osteosarcoma patients.

In this retrospective, two-center study we found that presence of metastasis at diagnosis, primary lesion at pelvis, and poor histologic response were significant unfavorable prognostic factors in the patients with osteosarcoma. These findings are also generally supported by many other reports [5] [7] [11] [13], not just for specific age group but for all the osteosarcoma patients. However, the proportion of metastasis at diagnosis was significantly higher in $20-40$ years of age group in our study. We assume that this is due to late timing of diagnosis caused from their relatively late visit to hospital when suspicious symptoms or pain were presented, which may arise from their unstable socioeconomic status in Korea, therefore more extensive research about this phenomenon should be performed in the near future.

\section{Conclusion}

Upon multivariate analysis, primary lesion at pelvis and poor histologic response maintained significant poor prognostic values on the outcome of osteosarcoma in 20 - 40 years of age group, but these factors were not age-specific characteristics. However, metastasis at diagnosis was significantly more found at the $20-40$ years of aged group. But for 10-year OS and EFS rates, these patients presented relatively good prognosis, in spite of significantly higher proportion of metastasis at diagnosis compared to the other age groups. This relative overtake of longer-term survival rates in these patients aged 20 - 40 years is an unique finding in our study; therefore more studies will be needed to find out whether this tendency is race-specific or not. In conclusion, if expeditious workups to prevent 
late diagnosis can be performed in young adult patients when osteosarcoma is suspected, the prognosis would be much better than any other age groups. Also, appropriate treatment modalities, and meticulous follow-ups should be kept in mind for this young adult osteosarcoma patients.

\section{References}

[1] Ottaviani, G. and Jaffe, N. (2009) The Epidemiology of Osteosarcoma. Cancer Treatment and Research, 152, 3-13. https://doi.org/10.1007/978-1-4419-0284-9_1

[2] Bleyer, A. and Barr, R. (2009) Cancer in Young Adults 20 to 39 Years of Age: Overview. Seminars in Oncology, 36, 194-206.

https://doi.org/10.1053/j.seminoncol.2009.03.003

[3] Adolescent and Young Adult Oncology Progress Review Group (2006) Closing the Gap: Research and Care Imperatives for Adolescents and young Adults with Cancer. NIH Pub. No. 06-6067. National Institutes of Health, Bethesda. http://planning.cancer.gov/library/AYAO_PRG_Report_2006_FINAL.pdf

[4] Bleyer, A., Barr, R., Hayes-Lattin, B., Thomas, D., Ellis, C. and Anderson, B. (2008) The Distinctive Biology of Cancer in Adolescents and Young Adults. Nature Reviews. Cancer, 8, 288-298. https://doi.org/10.1038/nrc2349

[5] Janeway, K.A., Barkauskas, D.A., Krailo, M.D., et al. (2012) Outcome for Adolescent and Young Adult Patients with Osteosarcoma: A Report from the Children's Oncology Group. Cancer, 118, 4597-4605. https://doi.org/10.1002/cncr.27414

[6] Union for International Cancer Control (2004) OSTEOSARCOMA: 2014 Review of Cancer Medicines on the WHO List of Essential Medicines. WHO Expert Committees.

http://www.who.int/selection_medicines/committees/expert/20/applications/Osteos arcoma.pdf?ua $=1$

[7] Bielack, S.S., Kempf-Bielack, B., Delling, G., et al. (2002) Prognostic Factors in High-Grade Osteosarcoma of the Extremities or Trunk: An Analysis of $1702 \mathrm{~Pa}-$ tients Treated on Neoadjuvant Cooperative Osteosarcoma Study Group Protocols. Journal of Clinical Oncology, 20, 776-790. https://doi.org/10.1200/JCO.2002.20.3.776

[8] Malawer, M.M., Helman, L.J. and O'Sullivan, B. (2004) Sarcomas of Bone. In: DeVita, V.T., Hellman, S. and Rosenberg, S.A., Eds., Cancer. Principles and Practice of Oncology, Vol. 2, 7th Edition, Lippincott Williams and Wilkins, Philadelphia.

[9] Kaplan, E.L. and Meier, P. (1958) Nonparametric Observations from Incomplete Observations. Journal of the American Statistical Association, 53, 457-481. https://doi.org/10.1080/01621459.1958.10501452

[10] Gurney, J.G., Severson, R.K., Davis, S. and Robison, L.L. (1995) Incidence of Cancer in Children in the United States. Sex-, Race-, and 1-Year Age-Specific Rates by Histologic Type. Cancer, 75, 2186-2195.

https://doi.org/10.1002/1097-0142(19950415)75:8<2186::AID-CNCR2820750825>3. $\underline{0 . \mathrm{CO} ; 2-\mathrm{F}}$

[11] Bacci, G., Longhi, A., Versari, M., et al. (2006) Prognostic Factors for Osteosarcoma of the Extremity Treated with Neoadjuvant Chemotherapy: 15-Year Experience in 789 Patients Treated at a Single Institution. Cancer, 106, 1154-1161. https://doi.org/10.1002/cncr.21724

[12] Grimer, R.J., Cannon, S.R., Taminiau, A.M., et al. (2003) Osteosarcoma over the Age of Forty. European Journal of Cancer, 39, 157-163. 
https://doi.org/10.1016/S0959-8049(02)00478-1

[13] Hagleitner, M.M., Hoogerbrugge, P.M., van der Graaf, W.T., Flucke, U., Schreuder, H.W. and Te Loo, D.M. (2011) Age as Prognostic Factor in Patients with Osteosarcoma. Bone, 49, 1173-1177. https://doi.org/10.1016/j.bone.2011.08.014

[14] Harting, M.T., Lally, K.P., Andrassy, R.J., et al. (2010) Age as a Prognostic Factor for Patients with Osteosarcoma: An Analysis of 438 Patients. Journal of Cancer Research and Clinical Oncology, 136, 561-570. https://doi.org/10.1007/s00432-009-0690-5

[15] Picci P. (2007) Osteosarcoma: What Did We Learn from the Paediatric Experience for Adolescents and Young Adults? EJC Supplements, 5, 227-234. https://doi.org/10.1016/S1359-6349(07)70044-7

[16] Fuchs, B., Hoekzema, N., Larson, D.R., Inwards, C.Y. and Sim, F.H. (2009) Osteosarcoma of the Pelvis: Outcome Analysis of Surgical Treatment. Clinical Orthopaedics and Related Research, 467, 510-518. https://doi.org/10.1007/s11999-008-0495-x

[17] Isakoff, M.S., Barkauskas, D.A., Ebb, D., Morris, C. and Letson, G.D. (2012) Poor Survival for Osteosarcoma of the Pelvis: A Report from the Children's Oncology Group. Clinical Orthopaedics and Related Research, 470, 2007-2013. https://doi.org/10.1007/s11999-012-2284-9

[18] Ozaki, T., Flege, S., Kevric, M., et al. (2003) Osteosarcoma of the Pelvis: Experience of the Cooperative Osteosarcoma Study Group. Journal of Clinical Oncology, 21, 334-341. https://doi.org/10.1200/JCO.2003.01.142

[19] Parry, M.C., Laitinen, M., Albergo, J., et al. (2016) Osteosarcoma of the Pelvis. The Bone \& Joint Journal, 98, 555-563. https://doi.org/10.1302/0301-620X.98B4.36583

[20] Bielack, S., Jürgens, H., Jundt, G., et al. (2009) Osteosarcoma: The COSS Experience. Cancer Treatment and Research, 152, 289-308. https://doi.org/10.1007/978-1-4419-0284-9_15

[21] Meyers, P.A., Schwartz, C.L., Krailo, M.D., et al. (2008) Osteosarcoma: The Addition of Muramyl Tripeptide to Chemotherapy Improves Overall Survival-A Report from the Children's Oncology Group. Journal of Clinical Oncology, 26, 633-638. https://doi.org/10.1200/JCO.2008.14.0095

[22] Mialou, V., Philip, T., Kalifa, C., et al. (2005) Metastatic Osteosarcoma at Diagnosis: Prognostic Factors and Long-Term Outcome-The French Pediatric Experience. Cancer, 104, 1100-1109. https://doi.org/10.1002/cncr.21263

[23] Hauben, E.I., Weeden, S., Pringle, J., Van Marck, E.A. and Hogendoorn, P.C. (2002) Does the Histological Subtype of High-Grade Central Osteosarcoma Influence the Response to Treatment with Chemotherapy and Does It Affect Overall Survival? A Study on 570 Patients of Two Consecutive Trials of the European Osteosarcoma Intergroup. European Journal of Cancer, 38, 1218-1225.

https://doi.org/10.1016/S0959-8049(02)00037-0

[24] Bacci, G., Bertoni, F., Longhi, A., et al. (2003) Neoadjuvant Chemotherapy for High-Grade Central Osteosarcoma of the Extremity: Histologic Response to Preoperative Chemotherapy Correlates with Histologic Subtype of the Tumor. Cancer, 97, 3068-3075. https://doi.org/10.1002/cncr.11456

[25] Goorin, A.M., Schwartzentruber, D.J., Devidas, M., et al. (2003) Presurgical Chemotherapy Compared with Immediate Surgery and Adjuvant Chemotherapy for Nonmetastatic Osteosarcoma: Pediatric Oncology Group Study POG-8651. Journal of Clinical Oncology, 21, 1574-1580. https://doi.org/10.1200/JCO.2003.08.165

[26] Miwa, S., Takeuchi, A., Ikeda, H., et al. (2013) Prognostic Value of Histological Response to Chemotherapy in Osteosarcoma Patients Receiving Tumor-Bearing Fro- 
zen Autograft. PLoS ONE, 8, e71362. https://doi.org/10.1371/journal.pone.0071362

[27] Ford, S., Saithna, A., Grimer, R.J. and Picci, P. (2004) Comparison of the Outcome of Conventional Osteosarcoma at Two Specialist International Orthopaedic Oncology Centres. Sarcoma, 8, 13-18. https://doi.org/10.1080/13577140410001679202

[28] Faisham, W.I., Mat Saad, A.Z., Alsaigh, L.N., et al. (2017) Prognostic Factors and Survival Rate of Osteosarcoma: A Single-Institution Study. Asia-Pacific Journal of Clinical Oncology, 13, e104-e110. https://doi.org/10.1111/ajco.12346

[29] Provisor, A.J., Ettinger, L.J., Nachman, J.B., et al. (1997) Treatment of Nonmetastatic Osteosarcoma of the Extremity with Preoperative and Postoperative Chemotherapy: A Report from the Children's Cancer Group. Journal of Clinical Oncology, 15, 76-84. https://doi.org/10.1200/JCO.1997.15.1.76

[30] Whelan, J.S., Jinks, R.C., McTiernan, A., et al. (2012) Survival from High-Grade Localised Extremity Osteosarcoma: Combined Results and Prognostic Factors from Three European Osteosarcoma Intergroup Randomised Controlled Trials. Annals of Oncology, 23, 1607-1616. https://doi.org/10.1093/annonc/mdr491 